\title{
Tension Strength Prediction of Transverse Branch Plate-to- Rectangular Joint with Concrete Filling
}

\author{
Zhihua Xiong \\ Northwest A\&F University, Yangling, Shaanxi, China \\ xiongrhibua_2013@126.com, bttps://orcid.org/0000-0001-8796-1004 \\ Yongjian Liu, Bin Liu, Lei Jiang \\ Chang'an University, Xi'an, Shaanxi, China \\ steellyj@126.com,513499836@qq.com,78874912@qq.com
}

\begin{abstract}
This paper predicts the tension strength of Concrete-filled Branch Plate-to-Rectangular Hollow (CBPRH) joint by conducting experimental and theoretical analysis. A total of $46 \mathrm{X}$-joints with different geometric parameters were investigated, in which 4 specimens were tested under ultimate tension and 42 specimens were numerically analyzed. The joint's strength, failure mode and load-displacement curve were obtained. Perfobond Leister Rib (PBR) was welded in part of the specimens to investigate its effect on joint's tensile performance. It is shown that the ultimate strength of transverse CBPRH joint benefit from grouting of chord and installation of PBR. The ultimate strength of CBPRH joint with PBR is larger than the counterpart without PBR. Tension strength equations were proposed for both CBPRH joints with and without PBR by nonlinear regression. The chord axial stress reduction factor was discussed and a modified equation originated from hollow joint was recommended for CBPRH joint. Connection efficiency was presented and compared among branch plate-to-rectangular hollow (BPRH) joint, CBPRH joint and CBPRH joint with PBR.
\end{abstract}

KEYwORDS. Branch plate; Concrete-filled tubular joint; Perfobond Leister; Rectangular hollow joint; Experimental investigation.

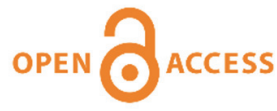

Citation: Xiong, Z.H., Liu, Y.J., Liu, B., Jiang, L., Tension Strength Prediction of Transverse Branch Plate-to-Rectangular Joint with Concrete Filling, Frattura ed Integrità Strutturale, 54 (2020) 136-152.

Received: 03.07.2020

Accepted: 22.08 .2020

Published: 01.10.2020

Copyright: (C) 2020 This is an open access article under the terms of the CC-BY 4.0, which permits unrestricted use, distribution, and reproduction in any medium, provided the original author and source are credited.

\section{INTRODUCTION}

$\mathrm{B}$

ranch Plate-to-Rectangular Hollow (BPRH) joint has been widely implemented in various structures. The typical BPRH joint usage includes: hanger plate connecting the rib in the arch bridge, steel braced frames in bridge and building structures, truss gusset plate joining chord and brace [1-3]. The tension strength calculation of BPRH in 
CIDECT provision was mainly derived from the experiments and FEM analysis [4-5 ]. For branch plate-to-circular hollow section, various literatures have been reported [6-8]. Recently, concrete-filled chord has been a prevailed technical practice in the tubular structure [9-11]. Besides concrete-filled circular section joint, elliptical section joint were also investigated about its structural performance [12-13]. Transverse and longitudinal BPRH joints with concrete-filling and other reinforcements' configurations are summarized in Tab. 1. However, strength prediction of transverse BPRH joint with concrete-filling has not been reported yet. Welding Perfobond Leister rib (PBR) in chord face in Tab. 1 and concretefilling have been found to be the significant alternatives to improve tension strength for RHS by the authors [14-15]. When it comes to BPRH joint, PBR's effect may be similar as to the RHS joint.

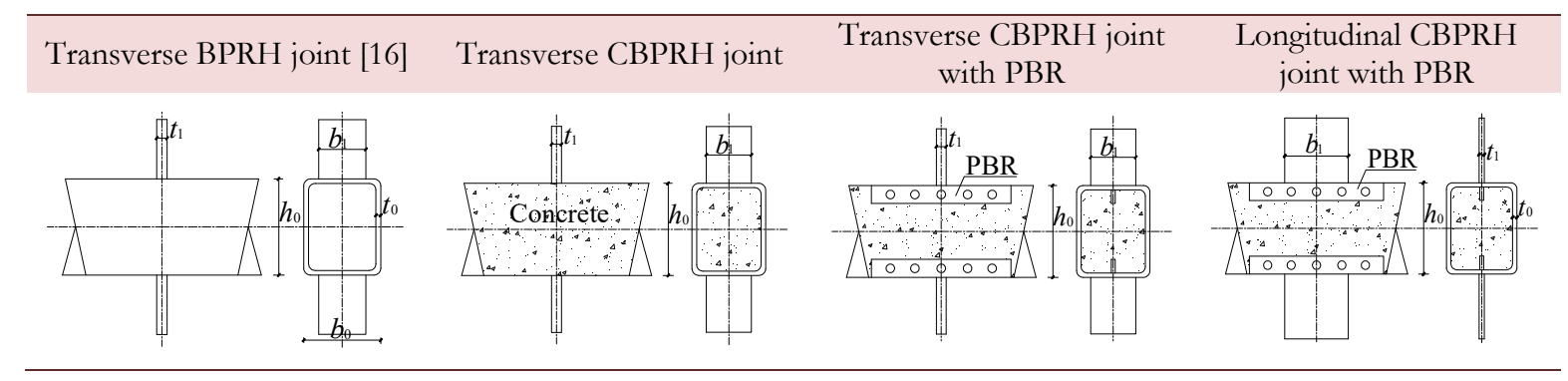

Table 1: Joint classification.

In order to investigate the effects of concrete-filling and PBR reinforcement of transverse CBPRH joint, firstly, a review of transverse BPRH tension strength was made. Then, the ultimate strength tests of longitudinal CBPRH joints with PBR were conducted and calibrated by FEM. After the verification of FEM, a comprehensive parametric analysis on transverse CBPRH joint was carried out. Failure modes of transverse CBPRH joint with and without PBR were investigated. Tension strength equation for transverse CBPRH joint has been proposed on the basis of nonlinear regression, which deals with the reinforcement of concrete and PBR separately. Besides, a modified chord axial stress reduction factor was suggested and connection efficiency was presented.

\section{OVERVIEW OF TRANSVERSE BPRH TENSION STRENGTH}

$\mathrm{W}$ ith regard to transverse BPRH joint, there are five failure modes: 1.chord plastification failure mode (FM1); 2 . punching shear failure mode (FM2); 3.combination of plastification and punching shear failure mode (FM3); 4.side wall failure mode (FM4); and 5. plate's local failure mode (FM5). When $\beta<0.85$, FM1 and FM2 need to be checked by expressions in Eqn.1 and Eqn.2 respectively, on the meantime, for $\tau<1$, FM5 could also govern hence it needs to be checked. FM3 is a mixture of the previous two modes FM1 and FM2, which has been observed and proposed by Davies and Packer [16]. The strength equation in literature [16] to predict FM3 is sophisticated in engineering calculation. When $\beta \approx 1$, the strength of transverse BPRH joint is governed by FM4.

$$
\begin{aligned}
& P_{1}=f_{y 0} t_{0}{ }^{2}\left[\frac{2+2.8 \beta}{\sqrt{1-0.9 \beta}}\right] Q_{f} \\
& P_{2}=0.58 f_{y 0} t_{0}\left(2 t_{1}+2 b_{e}\right)
\end{aligned}
$$

For the experimental research on BPRH joint's strength, it has been mainly carried out about twenty years ago by Kosteski [17]. Experiment on concrete-filled RHS X joint (CRHS) with PBR has indicated that the failure mode presents FM3. The mechanism of this compound failure mode has been owing to the dowel formed by PBR's hole and concrete [14-15]. In terms of the BPRH joint reinforced with both concrete and PBR, tension strength is accordingly improved, which can be inferred from the CRHS joint case. However, tension strength of the transverse CBPRH joint has not been reported in the earlier published studies. 


\section{BACKGROUND EXPERIMENT OF LONGITUDINAL CBPRH WITH PRB AND FEM VERIFICATION}

\section{Background experiment}

A total of four longitudinal CBPRH joints with PBR were tested in X-type configuration. Test specimens were divided into two groups according to the angle of inclination of branch plate to the axis of chord. The first group inclination angle was $60^{\circ}$, the second group inclination angle was $90^{\circ}$. The dimensions of the test specimens are summarized in Tab. 2. Longitudinal branch plate was welded to the chord in laboratory. The general detail of the joint is shown in Fig. 1. Both chord and PBR plate's thickness were $3 \mathrm{~mm}$. PBR was welded along the longitudinal direction of the chord with a length of $400 \mathrm{~mm}$. Radius of $7.5 \mathrm{~mm}$ hole was aligned with a distance of $35 \mathrm{~mm}$ in PBR as shown in Fig. 2. Branch plate's thickness was $8 \mathrm{~mm}$, and it was connected to the chord with a weld toe of $6 \mathrm{~mm}$. The concrete was casted into the chord after the completion of hollow BPRH joint's fabrication.
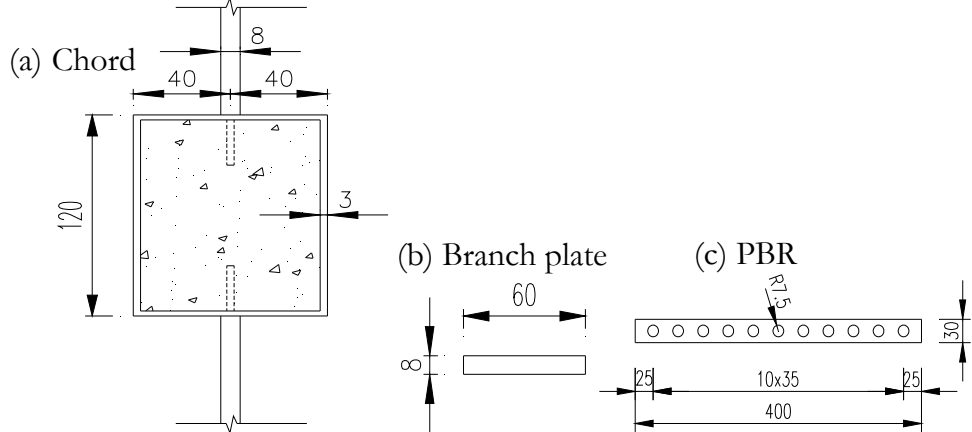

(d) Fabrication of the joint

Figure 1: Specimen's general section and fabrication (unit: $\mathrm{mm}$ ).

Steel (Chinese Grade Q235B) tensile coupons were carried out. The material properties of steel were obtained as follows: elastic modulus-2.03 $\times 10^{5} \mathrm{MPa}$, yield strength-232.6 MPa, ultimate strength-413.2 $\mathrm{MPa}$. A total of 6 standard concrete cubes with the nominal length of $150 \mathrm{~mm}$ was poured and cured with moisture for 28 days in accordance with the Chinese standard procedure (GB50010-2010). Due to the same fabrication date, the concrete properties were the same as the tests reported by the authors [14]. Compression strengths of six concrete cubes are summarized in Tab. 3. The specimens were tested in a $1000 \mathrm{kN}$ capacity instrument with two grips on top and bottom branch plate respectively. The specimens were loaded to failure with displacement control. Strain gauges were set on the chord face, whose position and tag were demonstrated in Fig. 2.

\begin{tabular}{cccccc}
\hline Specimens & $\begin{array}{c}\text { Chord } \\
\left(h_{0} \times b_{0} \times t_{0}\right)(\mathrm{mm})\end{array}$ & $\begin{array}{c}\text { Branch plate } \\
\left(b_{1} \times t_{1}\right)(\mathrm{mm})\end{array}$ & $b_{1} / b_{0}$ & $\theta_{0}$ & $\begin{array}{c}\text { Maximum load } \\
(\mathrm{kN})\end{array}$ \\
J-P-1 & $120 \times 80 \times 3$ & $60 \times 8$ & 0.75 & 60 & 103.1 \\
J-P-2 & $120 \times 80 \times 3$ & $60 \times 8$ & 0.75 & 60 & 118.9 \\
J-P-3 & $120 \times 80 \times 3$ & $60 \times 8$ & 0.75 & 90 & 99.6 \\
J-P-4 & $120 \times 80 \times 3$ & $60 \times 8$ & 0.75 & 90 & 114.0 \\
\hline
\end{tabular}

Table 2: Test specimens' detail.

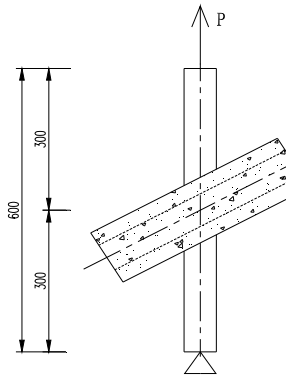

(a) Configuration of loading

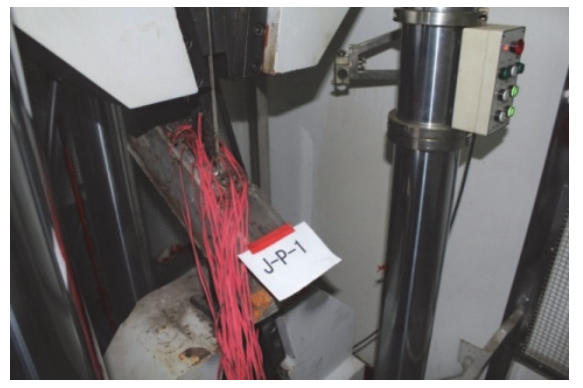

(b) Test rig

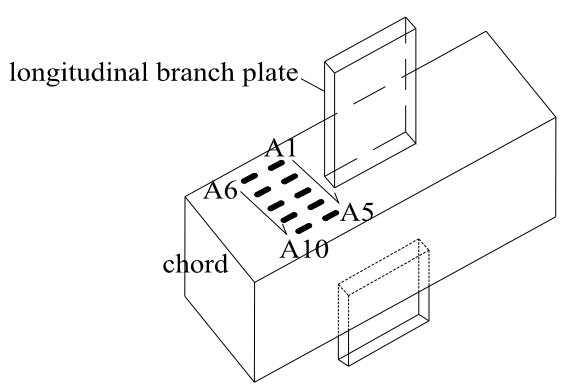

(c) Arrangement of strain gauges

Figure 2: Loading scheme of longitudinal CBPRH joint (unit: $\mathrm{mm}$ ). 


\begin{tabular}{ccc}
\hline No. & $\begin{array}{l}\text { Compressive cubic } \\
\text { strength }(\mathrm{MPa})\end{array}$ & Mean Value(Mpa) \\
1 & 50.36 & \\
2 & 49.94 & \\
3 & 51.30 & \\
4 & 47.98 & \\
5 & 50.64 & \\
6 & 51.28 \\
\hline
\end{tabular}

Table 3: Material properties of concrete.

Specimens' failure process is presented in Fig. 3. All specimens' failure mode turned up to large deformation in the chord face and crack at the intersection. As observed from Fig. 4, PBR dowel was totally smashed at the intersection between the branch plate and chord. As shown in Fig. 4, inclination angle makes trivial effects on the stiffness of longitudinal CBPRH joint with PBR, but it affects the peak load of the joint. Furthermore, joints of $\theta=90^{\circ}$ and $60^{\circ}$ both showed a good ductility during the loading process. Strain gauges of spot A3 and A8 in Fig. 5 reflected that there was considerable stress concentration in the intersection between chord and branch plate.

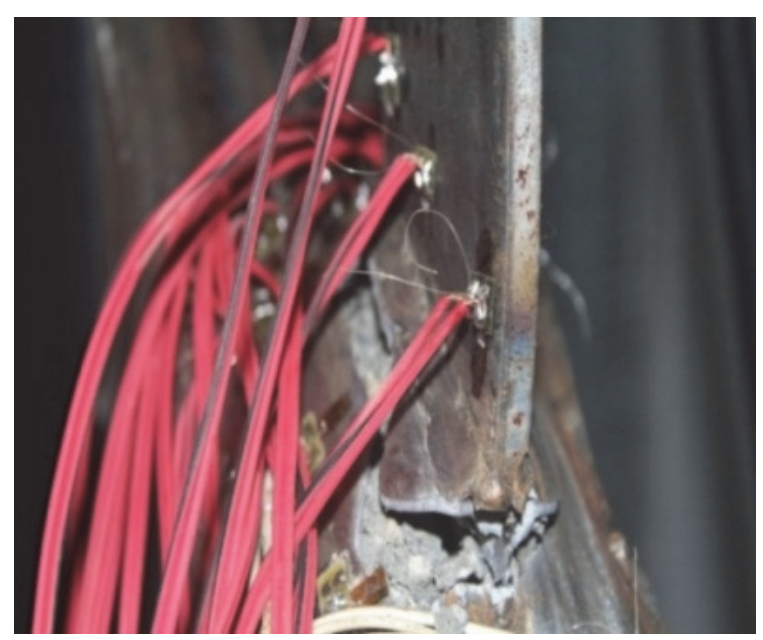

(a) $\theta=60^{\circ}$ Specimens' failure

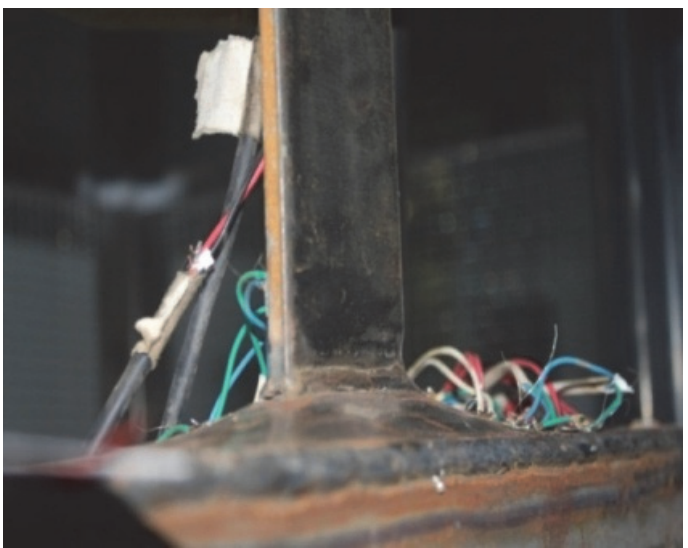

(b) $\theta=90^{\circ}$ Chord's deformation

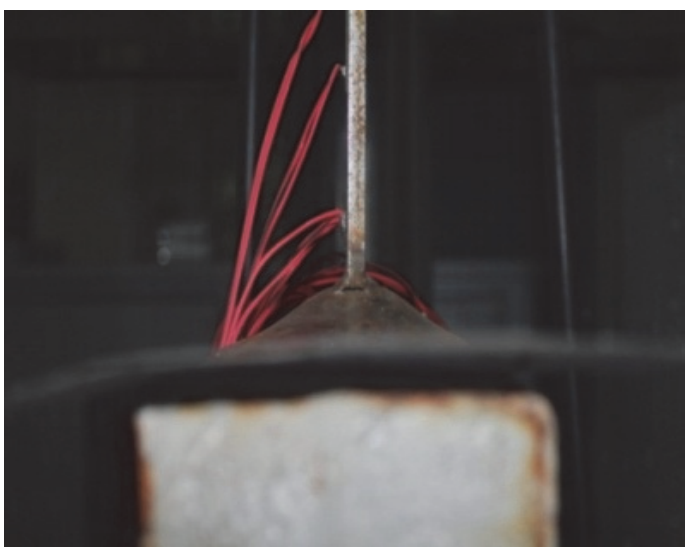

(c) $\theta=90^{\circ}$ effective width

Figure 3: Experimental specimens' failure mode. 


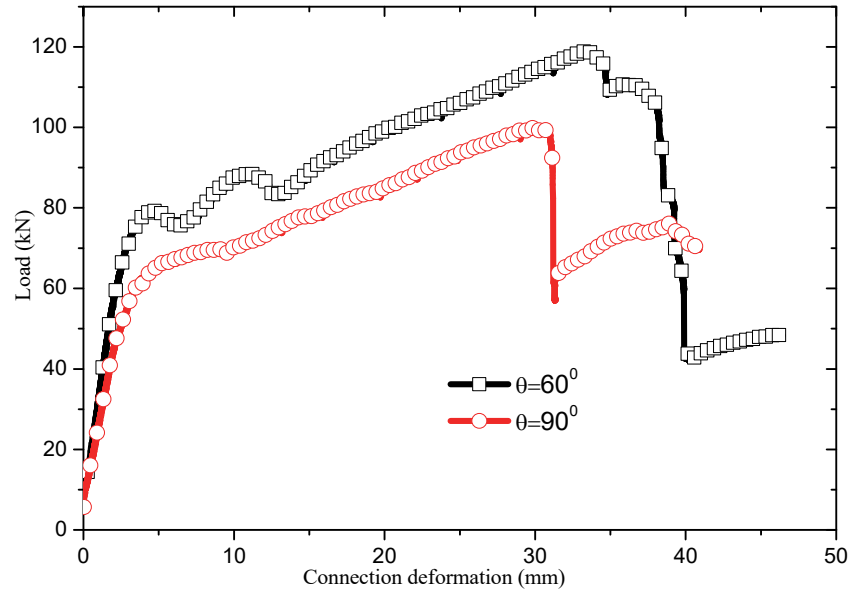

Figure 4: Inclination angle's effect on strength

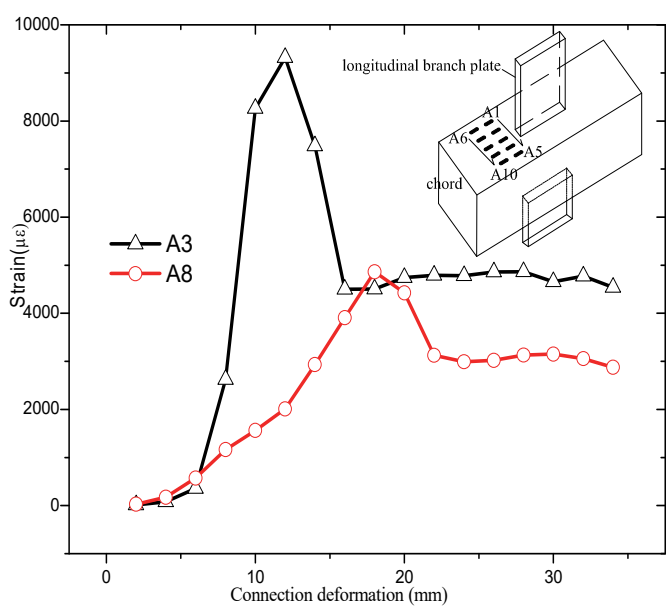

Figure 5: Chord face's strain-deformation curve of J-P-3

\section{FEM calibration}

The commercial software package ABAQUS was used for the finite element calibration. In terms of material constitutive relationship, the steel material took Von Mise yield criterion with isotropic hardening as its constitutive model. The true stress-true strain relationship derived from coupon test was utilized as input. The damage plasticity model in ABAQUS was used as the material constitution of concrete [18]. FIB model was adopted as the stress-strain relationship of concrete [19]. For concrete compression, uniaxial stress-strain curve was determined by Eqn.(3). For concrete tension, two bilinear approaches expressed in Eqn.(4) and Eqn.(5) were used.

$$
\begin{aligned}
& \frac{\sigma_{c}}{f_{c m}}=\frac{k \eta-\eta^{2}}{1+(k-2) \eta} \\
& \sigma_{c t}=f_{c t m}\left(1-0.8 \frac{w_{t}}{w_{t c}}\right) \quad w_{t} \leq w_{t c} \\
& \sigma_{c t}=f_{c t m}\left(0.25-0.05 \frac{w_{t}}{w_{t c}}\right) \quad w_{t c}<w_{t}<w_{t f}
\end{aligned}
$$

where, $\sigma_{\mathrm{c}}$ and $\varepsilon_{\mathrm{c}}$ are the stress and strain at any point on the compressive curve; $k=0.464 \cdot E_{\mathrm{c} 0} \varepsilon_{\mathrm{c} 1}\left(f_{\mathrm{cm}}\right)^{-2 / 3} ; f_{\mathrm{cm}}$ and $\varepsilon_{\mathrm{c} 1}$ are the maximum compressive stress and its corresponding strain; $\eta=\varepsilon_{\mathrm{c}} / \varepsilon_{\mathrm{c} 1} ; \varepsilon_{\mathrm{c} 1}=0.0026 ; \sigma_{\mathrm{ct}}$ is the stress at any point on the tensile curve; $w_{\mathrm{t}}$ is crack opening; $w_{\mathrm{tc}}=G_{\mathrm{f}} / f_{\mathrm{ctm}}$; the other parameters unmentioned are explained in Abbreviation. Dilation angle of concrete to control the plastic flow was assumed as $38^{0}$ according to Jankowiak [20].

Regarding to the contact, the concrete and chord were set as contact pairs as they were. The properties of contact pair were defined as: hard contact in normal direction and penalty friction in tangential direction with a friction coefficient of 0.3. PBR was modeled as embeded element and connected to chord simultaneously [14-15]. The 8-noded solid element with reduction integration (C3D8R) was selected. Mesh size for the intersection of joint and chord thickness direction was about $1.5 \mathrm{~mm}$, global element size was about $10 \mathrm{~mm}$. For $90^{\circ}$ joint, one-eighth model was built for symmetry. Branch plate's top was imposed a displacement load which was self-balanced for X joint. Since the joint was loaded to failure, the nonlinear geometric behavior was incorporated into the model.

Selected J-P-3's test ultimate deformation was identical to its corresponding FEM result in Fig. 6(a), the load-displacement curve of the test and FEM's curve shown in Fig. 6(b) matched. FEM simulation showed a good agreement with the test result. 


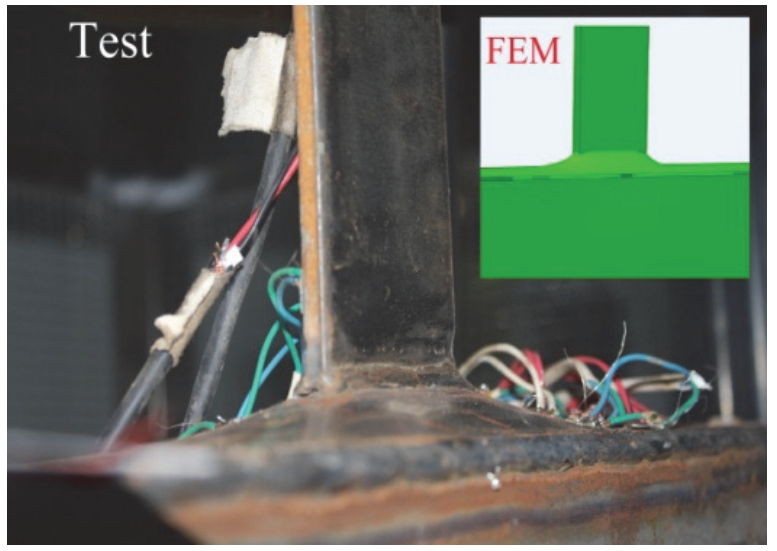

(a) Deformation

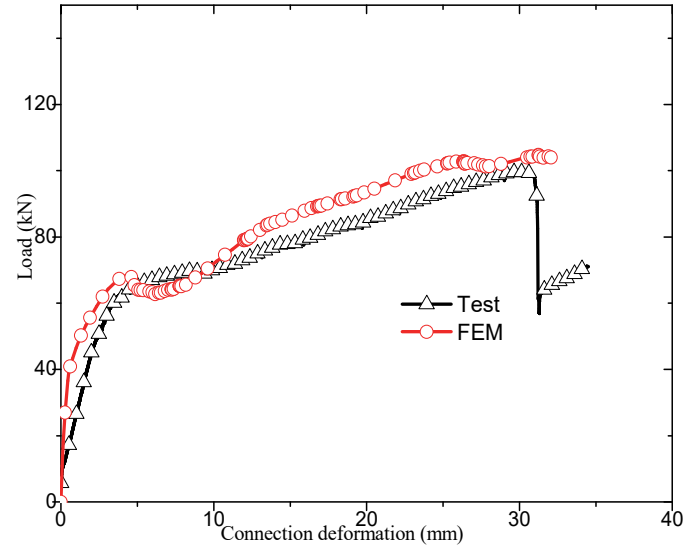

(b) Load-deformation curve

Figure 6: Comparison between J-P-3's test result and FEM

\section{TRANSVERSE CBPRH JOINT PARAMETRIC ANALYSIS}

A $s$ the FEM model has been proven its accuracy in simulating the tension failure of longitudinal CBPRH joints with PBR, a series of transverse CBPRH joints were built by FEM to investigate its tension strength. The modeling of joint and material constitutions were similar as described in Section FEM calibration except the material properties of steel. In parametric analysis, the steel was assumed as Q345 in Chinese Code, whose properties were as follow: elastic modulus $2.0 \times 10^{5} \mathrm{MPa}$, yield strength $345 \mathrm{MPa}$. From here on $\mathrm{CBPRH}$ joint denotes transverse $\mathrm{CBPRH}$ joint unless it is noted especially.

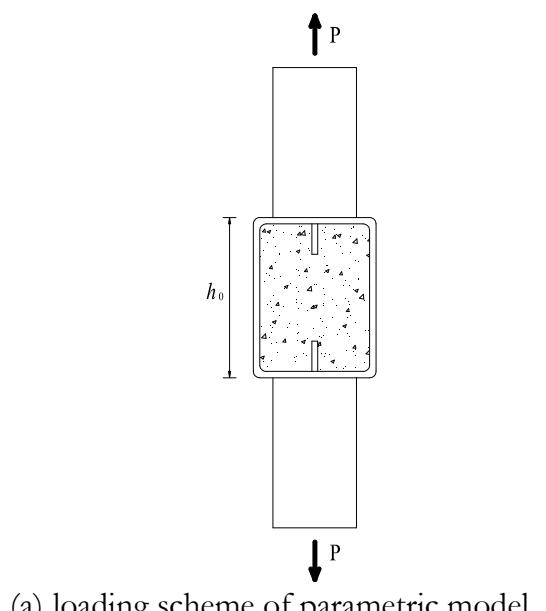

(a) loading scheme of parametric model

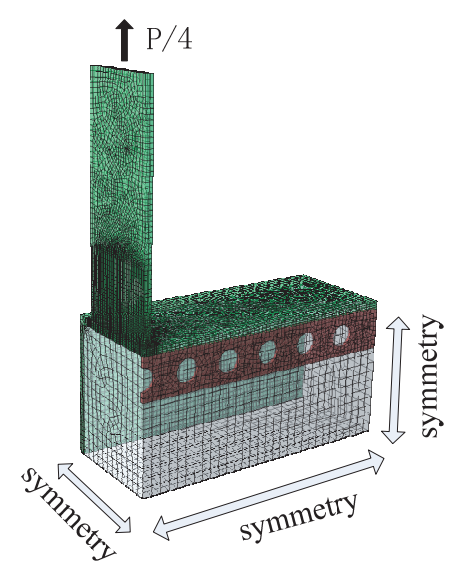

(b) One-eighth model

Figure 7: 1/8 Symmetry FEM of CBPRH joint with PBR

Only one-eighth of joint was modeled for the convenience of symmetry as shown in Fig. 7. The weld toe was defined as $18 \mathrm{~mm}$ between chord and the branch plate. The factors affecting joint's strength were involved in the parametric analysis, including: concrete grouting, the presence of PBR and other geometric parameters such as $\beta$, $\tau$. Thirty four specimens were analyzed in the parametric studies. The specimens' geometric dimensions are listed in Tab. 4 . The specimens were divided into two groups one of which was CBPRH joint without PBR and the other one was reinforced with PBR followed by a suffix "P". The specimens' $\beta$ and $\tau$ covered a range varying from 0.6 to 0.8 and 0.75 to 2 respectively, which was the most common practice in general steel tubular bridge. The specimens were analyzed as the same procedure stated in Section 3. For those joints named with suffix "P", PBR was welded along the longitudinal centerline of the chord; its height and thickness were $90 \mathrm{~mm}$ and $12 \mathrm{~mm}$ respectively. 


\begin{tabular}{|c|c|c|c|c|c|}
\hline Specimen No. & $\begin{array}{c}\text { Chord } \\
\left(h_{0} \times b_{0} \times t_{0}\right)(\mathrm{mm})\end{array}$ & $\begin{array}{c}\text { Branch plate } \\
b_{1}\end{array}$ & $\begin{array}{c}\text { Branch plate } \\
t_{1}\end{array}$ & $\tau\left(t_{1} / t_{0}\right)$ & $\beta\left(b_{1} / b_{0}\right)$ \\
\hline TT1,TT1P & \multirow{18}{*}{$600 \times 500 \times 16$} & 350 & 32 & 2 & 0.7 \\
\hline TT2,ТT2P & & 350 & 28 & 1.75 & 0.7 \\
\hline TT3,ТТ3Р & & 350 & 24 & 1.5 & 0.7 \\
\hline TT4,TT4P & & 350 & 20 & 1.25 & 0.7 \\
\hline TT5,TT5P & & 350 & 16 & 1 & 0.7 \\
\hline TT6,ТT6Р & & 350 & 12 & 0.75 & 0.7 \\
\hline TT7,TT7P & & 300 & 32 & 2 & 0.6 \\
\hline TT8,ТТ8Р & & 300 & 28 & 1.75 & 0.6 \\
\hline ТТ9,ТТ9Р & & 300 & 24 & 1.5 & 0.6 \\
\hline TT10,TT10P & & 300 & 20 & 1.25 & 0.6 \\
\hline TT11,TT11P & & 300 & 16 & 1 & 0.6 \\
\hline TT12,TT12P & & 400 & 32 & 2 & 0.8 \\
\hline TT13,TT13P & & 400 & 28 & 1.75 & 0.8 \\
\hline TT14,TT14P & & 400 & 24 & 1.5 & 0.8 \\
\hline TT15,TT15P & & 400 & 20 & 1.25 & 0.8 \\
\hline TT16,TT16P & & 400 & 16 & 1 & 0.8 \\
\hline TT17* & & 400 & 24 & 1.5 & 0.8 \\
\hline TT18* & & 400 & 24 & 1.5 & 0.8 \\
\hline
\end{tabular}

Table 4: Test specimens' detail, *TT17 and TT18 were set as the same dimension of TT14 with different concrete-filling (C30 and C60 respectively).

\section{Parametric analysis result}

The design tension strength $\left(P_{\mathrm{u}, 3 \%}\right)$ is defined as the first peak load in the load-displacement diagram if this occurs before a chord deformation of $3 \% \mathrm{~b}_{0}$, or the load at $3 \% \mathrm{~b}_{0}$ deformation if the peak load occurs after the $3 \%$ deformation [8]. From the comparison at the same $\beta$ for CBPRH joint, $\tau$ barely affects the strength of joints, which can be observed in Fig. 8(a). Comparing the sensitivity of $\beta$ and $\tau$ in Fig. 8(b), $\beta$ is the main factor which dominates the joint strength. As for the CBPRH joint with PBR, both $\beta$ and $\tau$ make significant impact on the strength of joints as presented by Fig. 8(c). This can be attributed to the different failure mechanism caused by the interaction between PBR and concrete.

To investigate the effect of concrete strength, TT17 and TT18 were filled with C30 and C60 (Chinese Grade) in prototype of TT14. Fig. 9 presents the load capacity of TT14, TT17 and TT18, it is found that the concrete strength makes trivial effect on the CBPRH strength. Hence, the concrete strength variation is omitted in the equation of CBPRH joint. The thickness of PBR in CRHS has been found that it has no obvious effects on the strength of joints if it is in a appropriated dimension range (Liu et al., 2013), which is therefore neglected in the discussion of CBPRH joint's strength hence.

\section{Failure mode discussion}

Previous comparison in Fig. 8(a) reflects that the strength improvement of CBPRH joint is owing to concrete grouting. Put specimens TT7, the strength is 1.76 times than BPRH joint. As it comes to joint TT7P with PBR, this increment even increases to 3.3 times. The significant improvement of strength owing to grouted concrete and PBR can be interpreted by Fig. 10, which plots a series comparison of transverse and shear plastic strain in chord face and branch plate in ultimate state. In terms of CBPRH joint without PBR in Fig. 10(a,b), the connecting face of chord turns out yield lines containing large area around the foot of branch plate, which is subject to the law of FM1. When PBR is welded inside the chord, the shear strain around the branch plate's foot accumulates swiftly in ultimate state with occurrence of chord yield lines as shown in Fig. 10 (c,d). In another word, tensile failure mechanism of CBPRH joint with PBR is subject to the law of FM3. 
Meanwhile, the above rule applies only to the thick branch plate. If the branch plate's thickness is equal or less than the chord's, like TT5 and TT11, as shown in Fig. $11(\tau=1)$, the plate's local yielding and chord's side wall yielding govern. Another point should be clarified, when the branch plate width is near the chord width namely $\beta \approx 1$, FM2 usually doesn't take place; hence, the failure mechanism of $\mathrm{CBPRH}$ joint $(\beta \approx 1)$ is different with the joint $\beta \leq 0.85$. Next, with the knowledge of failure mechanism of CBPRH joint, the strength equation for CBPRH joint and the joint with PBR could be developed.

\begin{tabular}{ccccc}
\hline Specimen & $\tau$ & $\beta$ & $P_{\mathrm{u}, 3 \%}$ & BPRH \\
TT1 & 2 & 0.7 & 1114.29 & 575.0 \\
TT2 & 1.75 & 0.7 & 1056.87 & 575.0 \\
TT3 & 1.5 & 0.7 & 947.54 & 575.0 \\
TT4 & 1.25 & 0.7 & 942.49 & 575.0 \\
TT5 & 1 & 0.7 & 878.86 & 575.0 \\
TT6 & 0.75 & 0.7 & 800.49 & 575.0 \\
TT7 & 2 & 0.6 & 845.1 & 479.2 \\
TT8 & 1.75 & 0.6 & 810.31 & 479.2 \\
TT9 & 1.5 & 0.6 & 770.28 & 479.2 \\
TT10 & 1.25 & 0.6 & 737.44 & 479.2 \\
TT11 & 1 & 0.6 & 697.53 & 479.2 \\
TT12 & 2 & 0.8 & 1368.66 & 707.7 \\
TT13 & 1.75 & 0.8 & 1267.27 & 707.7 \\
TT14 & 1.5 & 0.8 & 1197.99 & 707.7 \\
TT15 & 1.25 & 0.8 & 1126.54 & 707.7 \\
TT16 & 1 & 0.8 & 1040.53 & 707.7 \\
\hline
\end{tabular}

Table 5: Analysis result of CBPRH joint.

\begin{tabular}{ccccc}
\hline Specimen & $\tau$ & $\beta$ & $P_{\mathrm{u}, 3 \%}$ & BPRH \\
TT1P & 2 & 0.7 & 1761.9 & 575.0 \\
TT2P & 1.75 & 0.7 & 1664.5 & 575.0 \\
TT3P & 1.5 & 0.7 & 1545.4 & 575.0 \\
TT4P & 1.25 & 0.7 & 1373.1 & 575.0 \\
TT5P & 1 & 0.7 & 1169.5 & 575.0 \\
TT6P & 0.75 & 0.7 & 884.4 & 575.0 \\
TT7P & 2 & 0.6 & 1583.0 & 479.2 \\
TT8P & 1.75 & 0.6 & 1492.3 & 479.2 \\
TT9P & 1.5 & 0.6 & 1383.8 & 479.2 \\
TT10P & 1.25 & 0.6 & 1226.5 & 479.2 \\
TT11P & 1 & 0.6 & 1038.8 & 479.2 \\
TT12P & 2 & 0.8 & 2038.8 & 707.7 \\
TT13P & 1.75 & 0.8 & 1907.4 & 707.7 \\
TT14P & 1.5 & 0.8 & 1754.2 & 707.7 \\
TT15P & 1.25 & 0.8 & 1655.3 & 707.7 \\
TT16P & 1 & 0.8 & 1310.5 & 707.7 \\
\hline
\end{tabular}

Table 6: Analysis result of CBPRH joint with PBR. 


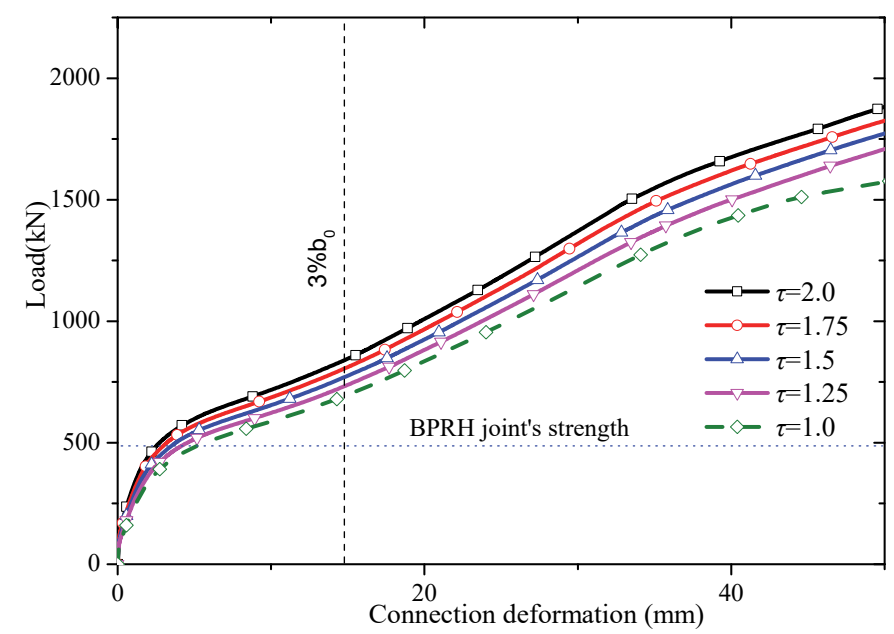

(a) $\beta=0.6$ (TT7-T'T11).

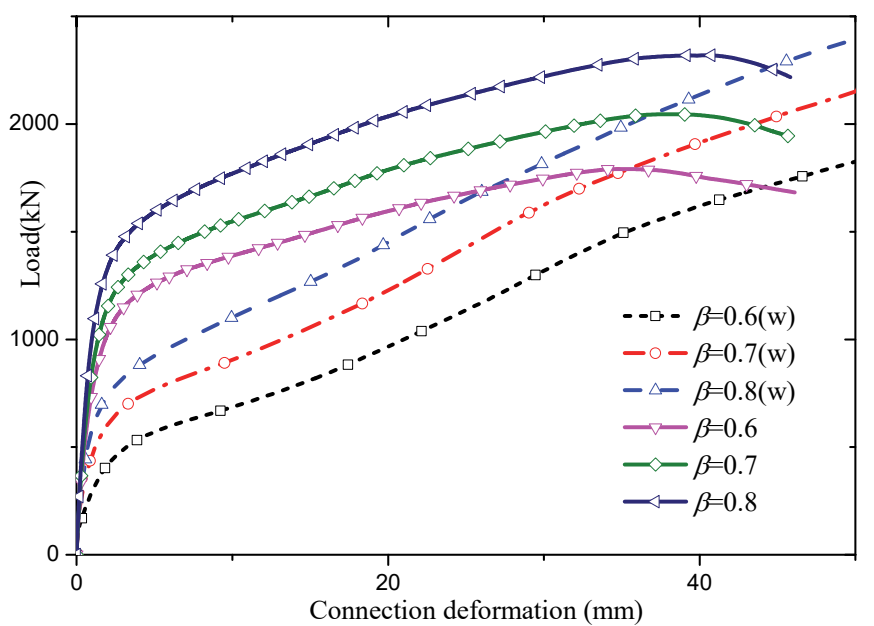

(b) $\tau=1.75$ ( $w$ representing the joint without PBR).

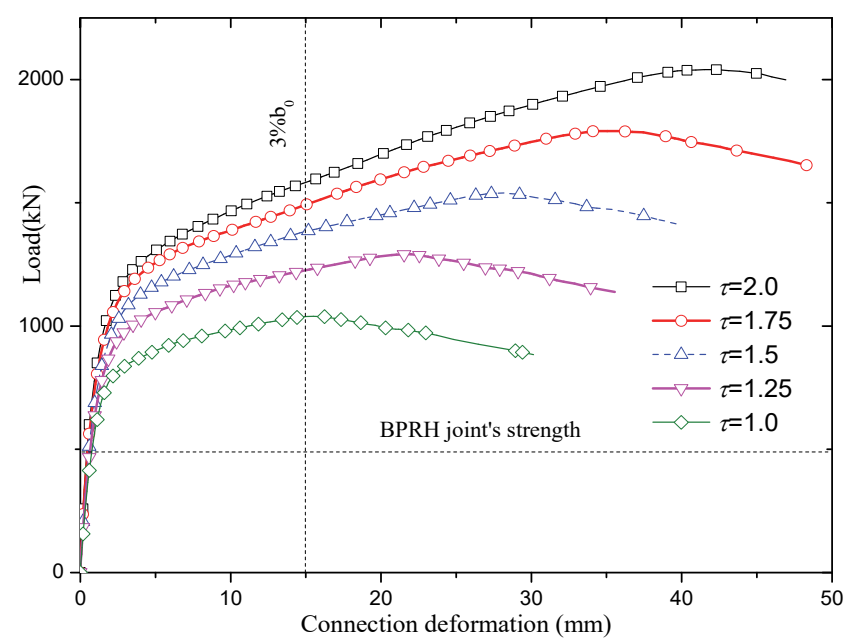

(c) $\beta=0.6$ (TT7P-TT11P)

Figure 8: Load-deformation curve of the parametric specimens 


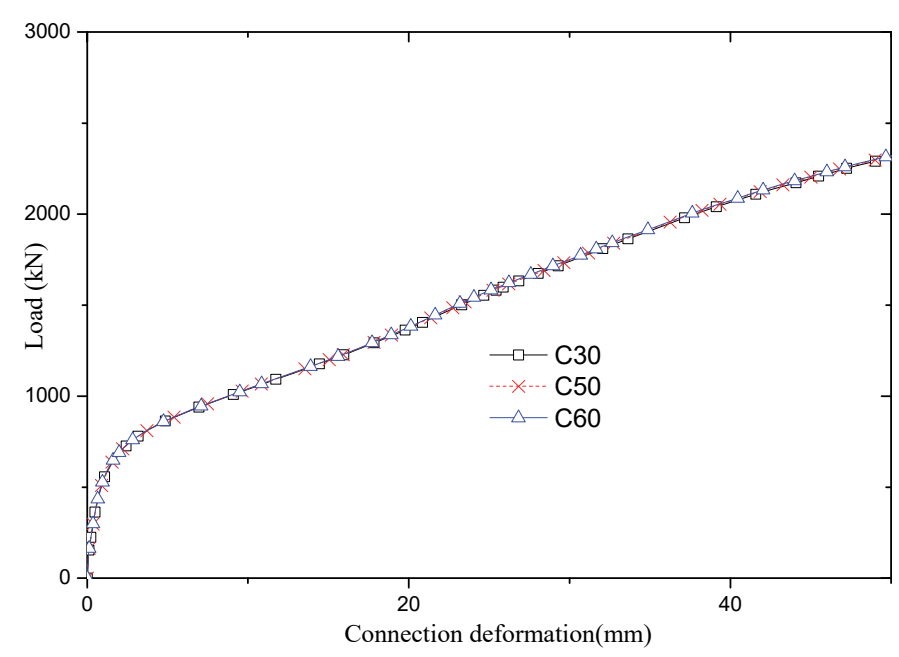

Figure 9: Grouted concrete's effect on joint's strength

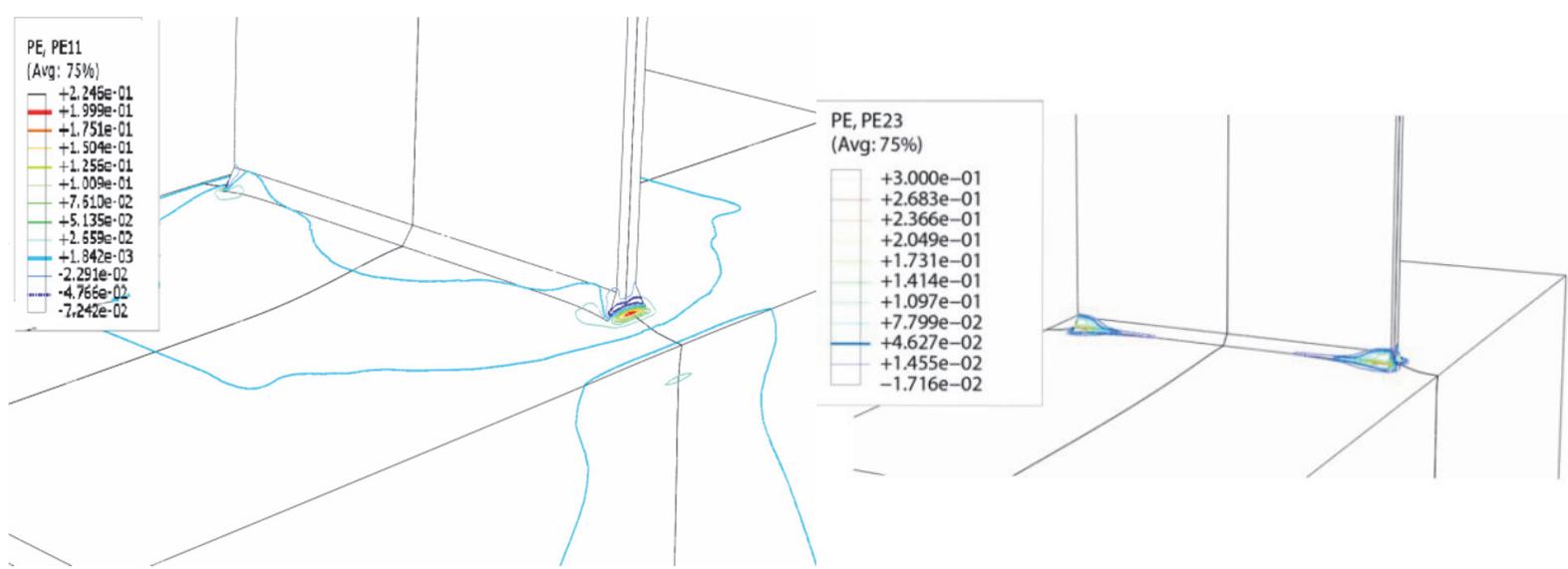

(a) transverse plastic strain of 'TT14's chord $\left(3 \% b_{0}\right)$

(b) shear plastic strain of T'T14's chord $\left(3 \% b_{0}\right)$

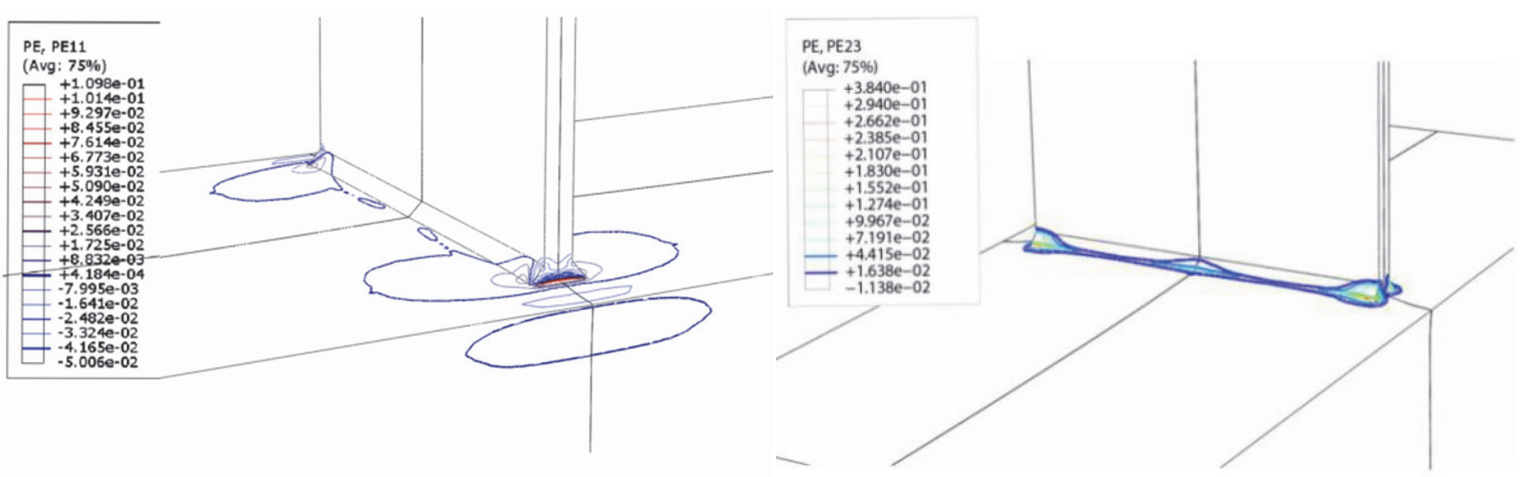

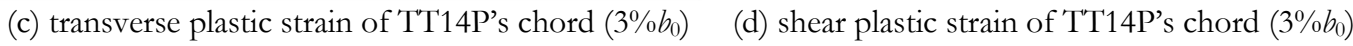

Figure 10: Failure modes of TT14 and TT14P. 


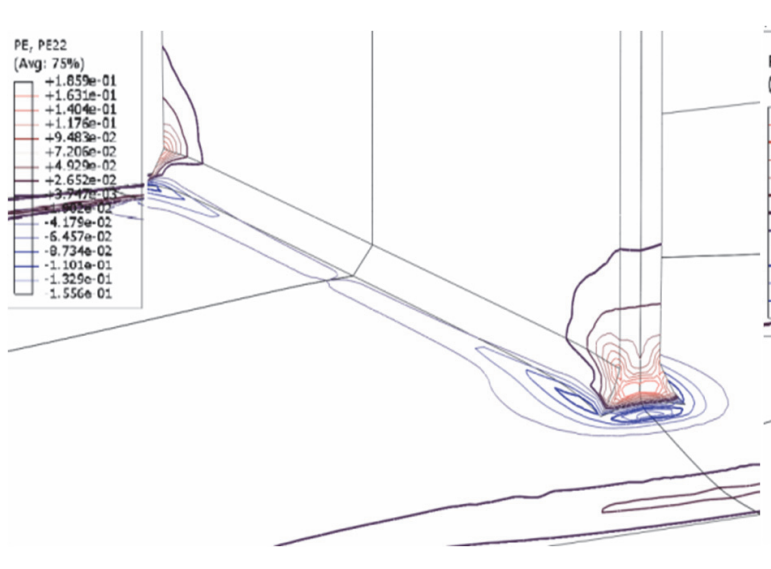

(a) branch plate's local plastic strain of TT5

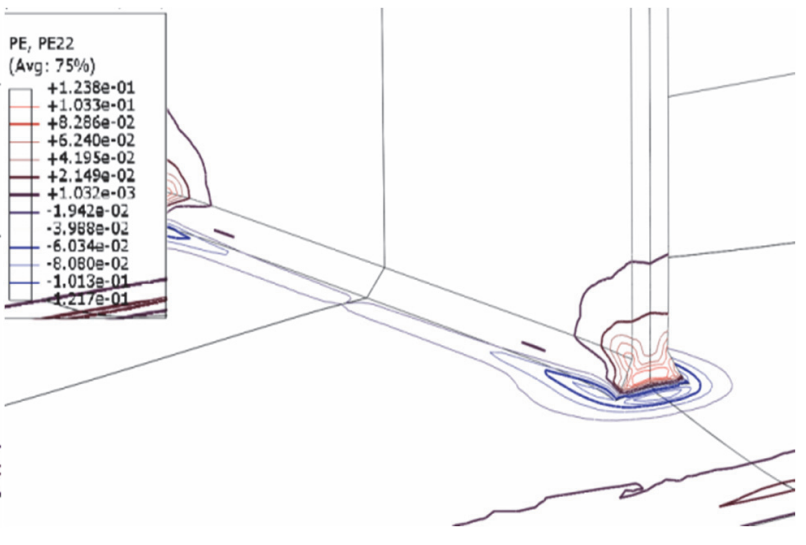

(b) branch plate's local plastic strain of TT11

Figure 11: Failure modes of TT5 and TT11

\section{TRANSVERSE CBPRH JOINT STRENGTH EQUATION}

\section{Design formula}

A ccording to the above discussion, when $\beta \leq 0.85$, CBPRH joint's tension failure mode is subject to FM1, while the failure mode of the joint with PBR is a mixture of FM1 and FM2, namely FM3. Davies and Packer [16] proposed a formula to predict FM3 of the hollow branch plate to RHS joint tension capacity. However, it is very sophisticated that rare application has been reported. In this paper, based on the previous hollow joint research, a formula is constructed as Eqn.(6). For CBPRH joint, $P_{\mathrm{u}}$ has only the first term $P_{1}$ in Eqn.(6), which evolves from FM1 to stand for chord plastification; the second term $P_{2}$ in Eqn. (6) representing FM2 is null. For CBPRH joint with PBR, the design strength is a combination of $P_{1}$ and $P_{2}$, which are expressed as Eqn.(7) and Eqn.(8) respectively. In Eqn.(8), $w_{4}$ and $w_{5}$ are weight factors on behalf of a comprehensive factors including: branch plate effective width and combination weight. $Q_{\mathrm{f}}$ is chord axial stress reduction function, which would be addressed in the next chapter.

$$
\begin{aligned}
& \mathrm{P}_{\mathrm{u}}=\left[\mathrm{P}_{1}\left(\mathrm{w}_{1}, \mathrm{w}_{2}, \mathrm{w}_{3}, \mathrm{~b}\right)+\mathrm{P}_{2}\left(\mathrm{w}_{4}, \mathrm{w}_{5}, \mathrm{t}_{1}\right)\right] \mathrm{Q}_{\mathrm{f}} \\
& \mathrm{P}_{1}=\mathrm{f}_{\mathrm{y} 0} \mathrm{t}_{0}{ }^{2}\left[\frac{\mathrm{w}_{1}+\mathrm{w}_{2} \beta}{\sqrt{1+\mathrm{w}_{3} \beta}}\right] \\
& P_{2}=w_{4} f_{y 0} t_{0} t_{1}+w_{5} f_{y 0} t_{0} b_{1}
\end{aligned}
$$

The function of Eqn.(6) has been constructed in MATLAB with given parameters, the ultimate capacity data and other geometric parameters have been input. Nonlinear regression has been made. Firstly, invariables $w_{1} \sim w_{3}$ in Eqn. (7) representing the strength of the CBPRH joint without PBR were fitted. When $P_{1}$ has been derived, $w_{4}$ and $w_{5}$ of CBPRH joint with PBR are then regressed. Tab. 7 summarizes the result of regression.

\begin{tabular}{ccccc}
\hline$w_{1}$ & $w_{2}$ & $w_{3}$ & $w_{4}$ & $w_{5}$ \\
3.1 & 9.61 & -0.1 & 1.5 & 0.15 \\
\hline
\end{tabular}

Table 7: Regressed invariables.

In order to validate Eqn.(6), additional FE specimens have been built which involve CBPRH joints with PBR and those without PBR. The material and boundary conditions are all the same with the ones in parametric analysis except the 
geometric dimensions. The dimensions of the additional FE specimens for verification are listed in Tab. 8. The comparison among the predicted strength by Eqn.(6), $P_{\mathrm{u}, 3 \%}$ by FEM and CIDECT Eqn.(1) are presented in Tab. 9. It is obvious that the proposed equation Eqn.(6) shows the least deviation to the calculated strength. Besides, the fitted strength is intentionally conservative in Tab. 9 since the defects of the un-filled corner of chord wall may not be avoided [21]. Pearson correlation coefficient has also been implemented to evaluate the legitimacy of the proposed Eqn.(6). Pearson correlation coefficient for CBPRH joint and the joint with PBR are 0.90 and 0.84 respectively, which proves a strong correlation between the data and equations. Scatter plot and correlation ellipse in Fig. 12 also indicate the accuracy of the equation.

\begin{tabular}{ccccccc}
\hline Specimens No. & $\begin{array}{c}\text { Chord } \\
\left(b_{0} \times b_{0} \times t_{0}\right) \\
(\mathrm{mm})\end{array}$ & $\begin{array}{c}\text { Branch Plate } \\
\left(b_{1}\right)\end{array}$ & $\begin{array}{c}\text { Branch Plate } \\
\left(t_{1}\right)\end{array}$ & $\tau\left(t_{1} / t_{0}\right)$ & $\beta\left(b_{1} / b_{0}\right)$ & PBR $(\mathrm{mm})$ \\
V1, V1P & & 240 & 24 & 2 & 0.6 & \\
V2, V2P & $500 \times 400 \times 12$ & 240 & 20 & 1.67 & 0.6 & $\mathrm{R}=25, t=10$ \\
V3, V3P & & 280 & 24 & 2 & 0.7 & \\
V4, V4P & & 280 & 16 & 1.33 & 0.7 & \\
\hline
\end{tabular}

Table 8: Dimensions of verification specimens

\begin{tabular}{ccccccc}
\hline \multirow{2}{*}{ Specimens No. } & $P_{\mathrm{u}, 3 \%}$ & \multicolumn{3}{c}{ Eqn.(6) } & Eqn.(2) & Failure mode \\
\cline { 3 - 5 } V1 & 472.6 & value & deviation & value & deviation & FM1 \\
V1P & 949.5 & 0.05 & 269.6 & 0.43 & - & FM3 \\
V2 & 439.2 & 846.9 & 0.10 & - & -16.4 & FM1 \\
V2P & 465.8 & 449.5 & 0.04 & 269.6 & - & FM3 \\
V3 & 598.8 & 813.8 & 0.09 & - & 0.42 & FM1 \\
V3P & 556.3 & 500.6 & 0.10 & 323.4 & - & FM3 \\
V4 & 1023.2 & 931.1 & 0.09 & - & 0.38 & FM1 \\
V4P & 519.2 & 500.6 & 0.04 & 323.4 & - & FM3 \\
\hline
\end{tabular}

Table 9: Comparison of tension strength by different equations

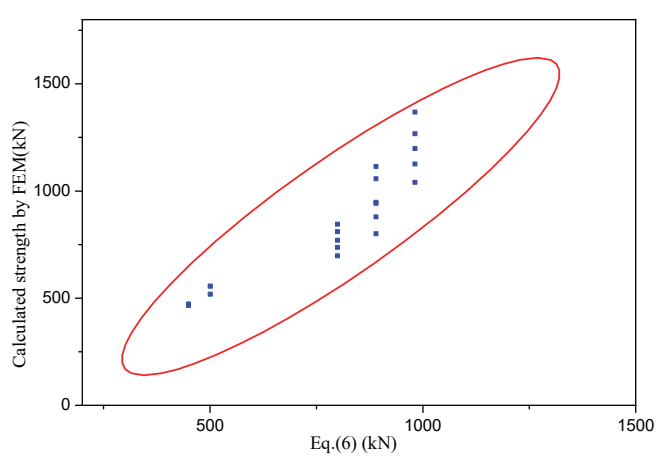

(a) CBPRH joint correlation ellipse

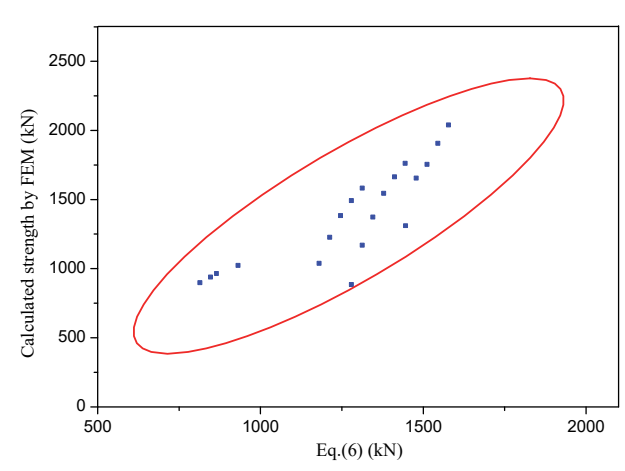

(b) CBPRH joint with PBR correlation ellipse

Figure 12: Correlation ellipse between calculated strength and Eqn.(6) 
Another point should be noted, as mentioned in $4^{\text {th }}$ chapter, when $\tau \leq 1$ the failure mode is far from FM3 and thus it's not included in the equation. Moreover, in bridge engineering practice, the branch plate thickness is usually larger than the chord's such as arch bridge rib hanger, namely $\tau>1$, therefore, the discussed equations are established under the assumption of $\tau \geq 1.25$.

\section{Chord axial stress reduction factor}

In the steel joint design, when the chord is under compression the design strength of the joint would decrease somehow depending on the stress of the chord wall. BPRH joint chord stress reduction factor $Q_{f}$ is proposed in CIDECT, which is expressed as Eqn. (9) and derived from yield line model [5]. In Eqn.(9), $n$ denotes the ratio of axial stress to yield stress, whose maximum and minimum are 1 and 0 respectively. $w_{6}$ is 0.03 for BPRH joint.

$$
Q_{f}=(1-n)^{w_{6} \gamma}
$$

However, for CBPRH joint, the concrete in chord provides a solid boundary to resist local yielding of chord wall. Therefore, $Q_{f}$ in CIDECT adopted for the hollow chord should be re-evaluated for the concrete-filled joint.

TT9, TT3 and TT14 with a variable $\beta$ of 0.6-0.8 were selected for the investigation of $Q_{f}$. The ultimate strength of noncompression axial stress joint $(n=0)$ has been summarized in Tab. 5. The FEM modeling of joint with axial stress was the same as described in $4^{\text {th }}$ chapter except a rigid plate was added on top of the chord. Axial compression was firstly loaded on this rigid plate and then distributed to the chord and concrete. The ultimate strengths of these joints under different chord axial stress were obtained by FEM analysis as shown in Tab. 10. The definition of $P_{\mathrm{u}}$ was also the same as discussed in $4^{\text {th }}$ chapter.

Each $Q_{f}$ curve of joints in Tab. 10 is plotted in Fig. 13. It was found that when $w_{6}=0.015 Q_{f}$ 's statistical coefficient of variation $(\mathrm{CoV})$ in Fig. 13 was only 6.7\%. Therefore, $w_{6}=0.015$ is recommended for the chord axial stress reduction of CBPRH joint. In terms of CBPRH joint with PBR, since its axial stiffening of PBR, $Q_{\mathrm{f}}$ could be adopted conservatively as the same as that of CBPRH joint.

\begin{tabular}{|c|c|c|c|c|c|c|c|c|}
\hline Specimens & $\begin{array}{c}\text { Chord } \\
\left(h_{0} \times b_{0} \times t_{0}\right)(\mathrm{mm})\end{array}$ & $\begin{array}{l}\text { Branch plate } \\
\left(b_{1} \times t_{1}\right)(\mathrm{mm})\end{array}$ & $\tau$ & $\beta$ & $\gamma$ & $n$ & $P_{\mathrm{u}}$ & $Q_{\mathrm{f}}$ \\
\hline \multirow{6}{*}{ TT3 } & \multirow{6}{*}{$600 \times 500 \times 16$} & \multirow{6}{*}{$350 \times 24$} & \multirow{6}{*}{1.5} & \multirow{6}{*}{0.7} & \multirow{6}{*}{15.63} & 0 & 947.54 & 1 \\
\hline & & & & & & 0.5 & 865 & 0.91 \\
\hline & & & & & & 0.6 & 845.4 & 0.89 \\
\hline & & & & & & 0.7 & 820.9 & 0.87 \\
\hline & & & & & & 0.8 & 772.9 & 0.81 \\
\hline & & & & & & 0.88 & 602.3 & 0.64 \\
\hline \multirow{6}{*}{ TT9 } & \multirow{6}{*}{$600 \times 500 \times 16$} & \multirow{6}{*}{$300 \times 24$} & \multirow{6}{*}{1.5} & \multirow{6}{*}{0.6} & \multirow{6}{*}{15.63} & 0 & 770.28 & 1 \\
\hline & & & & & & 0.5 & 744.8 & 0.97 \\
\hline & & & & & & 0.6 & 720.8 & 0.94 \\
\hline & & & & & & 0.7 & 708.4 & 0.92 \\
\hline & & & & & & 0.8 & 582.4 & 0.76 \\
\hline & & & & & & 0.99 & 265.5 & 0.34 \\
\hline \multirow{6}{*}{ TT14 } & \multirow{6}{*}{$600 \times 500 \times 16$} & \multirow{6}{*}{$400 \times 24$} & \multirow{6}{*}{1.5} & \multirow{6}{*}{0.8} & \multirow{6}{*}{15.63} & 0 & 1197.99 & 1 \\
\hline & & & & & & 0.5 & 1105.1 & 0.92 \\
\hline & & & & & & 0.6 & 1078.3 & 0.90 \\
\hline & & & & & & 0.7 & 1047 & 0.87 \\
\hline & & & & & & 0.8 & 987.1 & 0.82 \\
\hline & & & & & & 0.88 & 753.8 & 0.63 \\
\hline
\end{tabular}

Table 10: Chord axial stress reduction. 


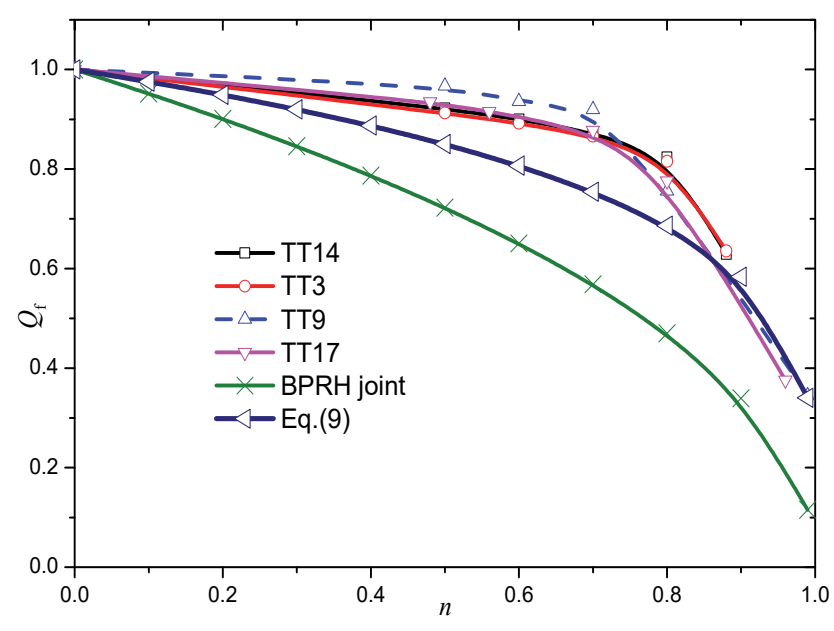

Figure 13: Proposed $\mathrm{Q}_{\mathrm{f}}$ for CBPRH joint.

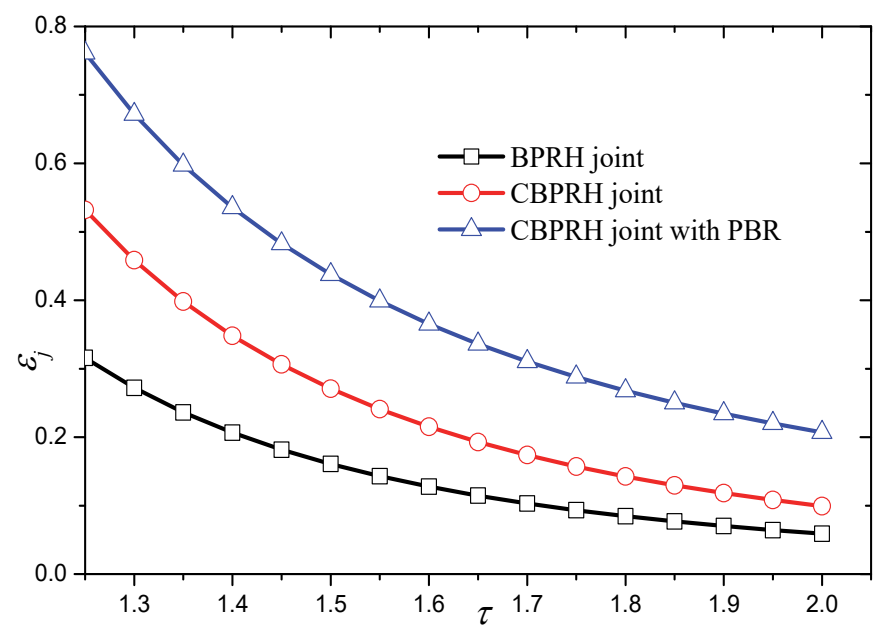

Figure 14: Connection efficiency's comparison among different joints

\section{CONNECTION EFFICIENCY}

7 he connection efficiency has been employed to compare structural advantages between different joint, which is defined as Eqn.(10). Substitute by Eqn.(6), Eqn.(10) becomes as Eqn.(11) and Eqn.(12) for the joint with and without PBR respectively.

$$
\begin{aligned}
& \varepsilon_{j}=P_{u} / t_{1} b_{1} f_{j 1} \\
& \varepsilon_{j}=Q_{f}\left[f_{y 0} t_{0}^{2}\left[\frac{3.1+9.61 \beta}{\sqrt{1-0.1 \beta}}\right]+1.5 f_{y 0} t_{0} t_{1}+0.15 f_{y 0} t_{0} b_{1}\right] \frac{1}{t_{1} b_{1} f_{y 1}} \\
& \varepsilon_{j}=Q_{f}\left[f_{y 0} t_{0}^{2}\left[\frac{3.1+9.61 \beta}{\sqrt{1-0.1 \beta}}\right]\right] \frac{1}{t_{1} b_{1} f_{y 1}}
\end{aligned}
$$

The geometric parameters and invariables from the specimens in Tab. 4 were assumed as: $f_{\mathrm{y} 0}=f_{\mathrm{y} 1}=f_{\mathrm{yp}}, Q_{\mathrm{f}}=1, \tau: 1.25 \sim 1.75$, $b_{1} / t_{1}: 12 \sim 22$. The connection efficiencies of BPRH, CBPRH and CBPRH joint with PBR are plotted in Fig. 14, which 
depicts a sensitive area of $\tau$ : ranging from 1.25 to 1.5 for the three types of joints. When $\beta=0.6 \tau=1.25$, CBRPH joint's $\varepsilon_{j}$ is 1.68 times than BRPH joint, while the joint with PBR $\varepsilon_{j}$ is 2.4 times than BRPH joint. Among the parameters of CBPRH joint with PBR, at given $\beta$, $\tau$ is more sensitive than $b_{1} / t_{1}$ as shown in Fig. 15(a), at given $b_{1} / t_{1}, \beta$ is more sensitive than $\tau$ as shown in Fig. 15(b).

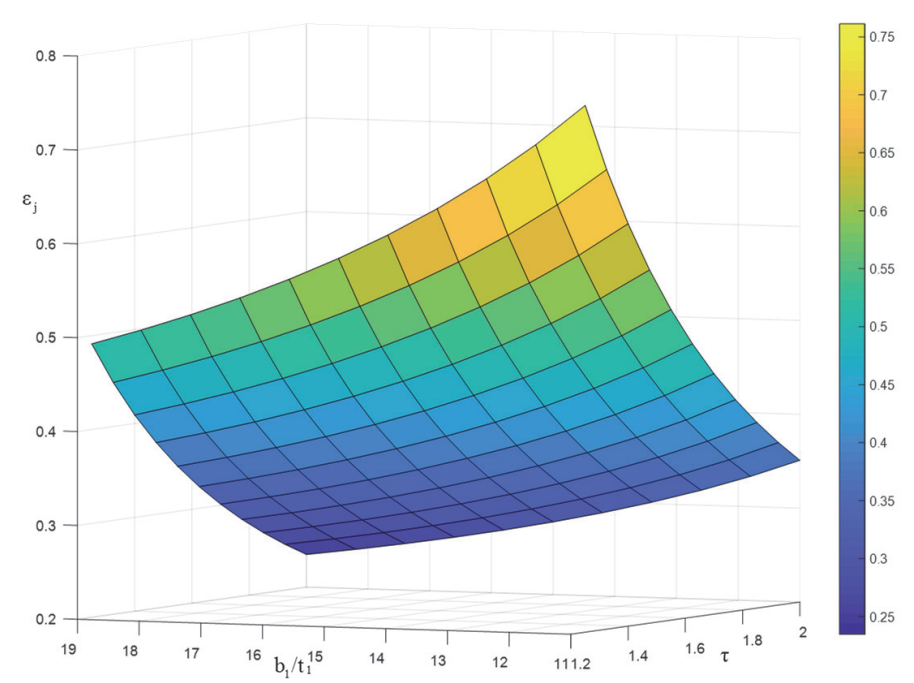

(a) $\beta=0.6$

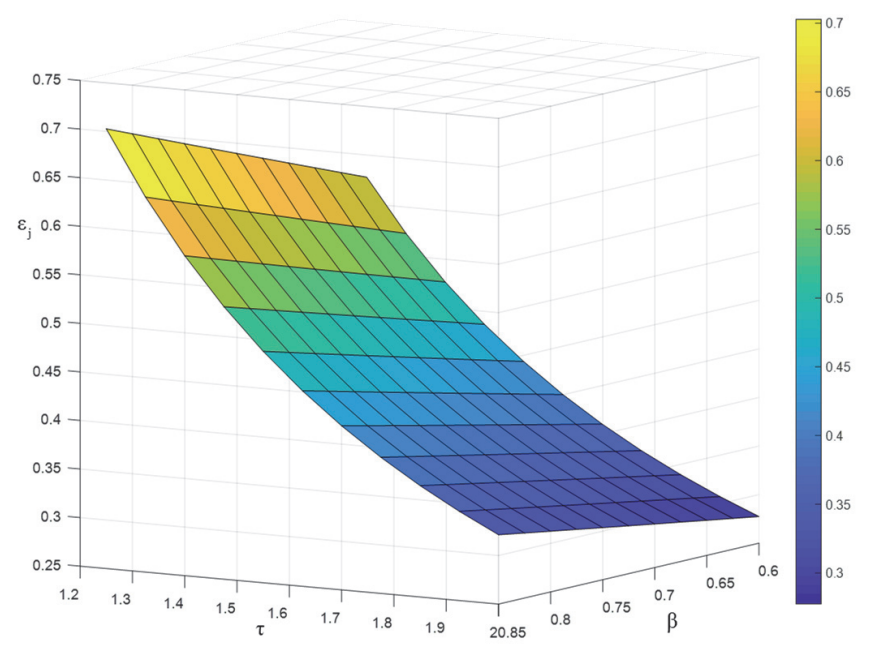

(b) $b_{1} / t_{1}=15$

Figure 15: Connection efficiency of CBPRH joint with PBR

In general, connection efficiency comparison indicates that grouted concrete and PBR are quite effective in improving the strength of BPRH joint. However, the welding of PBR adds additional fabrication procedure, which may increase the possibility of defects in the joint.

\section{CONCLUSIONS}

$\mathrm{U}$ ltimate test of longitudinal CBPRH joint with PBR was carried out, which has been used to validate against FE modeling for transverse CBPRH joint. For transverse BPRH joint, grouted concrete has significant improvement of joint's tension strength. Transverse CBPRH joint's failure mode has been investigated, which is subject to yield line theory. CBPRH joint's strength equation has been proposed on basis of hollow joint's theory (Eqn. (7)). The 
invariable $w_{6}$ of chord axial stress reduction function (Eqn. (9)) is recommended $w_{6}=0.15$. Parametric analysis of transverse CBPRH joint with PBR has been done to investigate the failure mode of the joint. It has been found that its failure mechanism is the combination of chord plastification and punching shear failure. The relevant factors affecting the joint strength such as: concrete strength, $\beta, b_{1} / t_{1}$ etc. have been discussed. With the capability to capture the compounded failure mechanism of the joint, the strength equation has been proposed (Eqn. (6)). To guarantee its accuracy, the equation has been tested by Pearson Correlation and a comparison between different tension strength equations has been made; the prediction by the equation shows a good agreement with the joint's tension strength. Connection efficiency has been presented by using the equation proposed in the paper. The efficiency of CBPRH joint with PBR surpasses CBPRH and BPRH joint. Among the geometric parameters of CBPRH joint with PBR, sensitive ranking in a descending order is: $\beta, \tau, b_{1} / t_{1}$. However, the welding of PBR adds additional fabrication procedure, which may increase the possibility of weld defect in the joint.

These conclusions are drawn under the circumstance of $\beta \leq 0.85$ and $\tau>1.25$. For $\beta \approx 1$, the CBPRH joint failure mode is far from the situation discussed in the paper, which needs to be further studied.

\section{AbBreviation}

\begin{tabular}{|c|c|c|c|}
\hline Symbol & Notation & Symbol & Notation \\
\hline$b_{0}$ & external width of RHS chord & $\beta$ & $\begin{array}{l}\text { width ratio between branch } \\
\text { plate and the chord }\end{array}$ \\
\hline$b_{1}$ & $\begin{array}{l}\text { external width of RHS branch plate } \\
\text { (perpendicular to the plane of the joint) }\end{array}$ & $b_{\mathrm{e}}$ & effective punching shear width \\
\hline CIDECT & $\begin{array}{c}\text { Comité International pour le } \\
\text { Développement et l'Etude de la } \\
\text { Construction Tubulaire }\end{array}$ & $\tau$ & $\begin{array}{l}\text { ratio between branch plate's } \\
\text { thickness and chord's thickness }\end{array}$ \\
\hline$f_{\mathrm{y} 0}$ & yield stress of the chord & $t_{0}$ & $\begin{array}{l}\text { thickness of hollow section } \\
\text { chord }\end{array}$ \\
\hline$b_{0}$ & external depth of RHS chord & $t_{1}$ & $\begin{array}{l}\text { thickness of hollow section } \\
\text { branch plate }\end{array}$ \\
\hline$b_{1}$ & external depth of branch plate & $\Delta_{\mathrm{u}}$ & $\begin{array}{c}\text { corresponding displacement at } \\
\text { the peak load }\end{array}$ \\
\hline$\theta$ & $\begin{array}{l}\text { inclined angle between branch plate } \\
\text { and the chord }\end{array}$ & $P_{\mathrm{u}}$ & $\begin{array}{l}\text { uniform design strength of the } \\
\text { joint }\end{array}$ \\
\hline$P_{1}$ & design strength of chord plastification & $P_{2}$ & $\begin{array}{l}\text { design strength of punching } \\
\text { shear failure }\end{array}$ \\
\hline$f_{c t m}$ & maximum tensile stress of concrete & $G_{f}$ & fracture energy of concrete \\
\hline PBL & Perfobond Leister in the slab & PBR & Perfobond Leister rib in joint \\
\hline RHS & Rectangular hollow section & CRHS & $\begin{array}{l}\text { concrete-filled rectangular } \\
\text { hollow section }\end{array}$ \\
\hline BPRH & $\begin{array}{l}\text { branch plate-to-rectangular hollow } \\
\text { section }\end{array}$ & CBPRH & $\begin{array}{l}\text { concrete-filled branch plate-to- } \\
\text { rectangular hollow section }\end{array}$ \\
\hline$Q_{\mathrm{f}}$ & chord axial stress reduction factor & $n$ & axial stress ratio \\
\hline$\gamma$ & $\begin{array}{l}\text { half width to thickness ratio of the } \\
\text { chord }\left(b_{0} / 2 t_{0}\right)\end{array}$ & & \\
\hline
\end{tabular}

\section{ACKNOWLEDGMENTS}

7 he research was supported by National Natural Science Foundation of China (Grant No. 51908422) and Elite Scholar Program of Northwest A\&F University (Grant No. Z111022001). 


\section{REFERENCES}

[1] Bae, K.W., Park, K.S., Choi, Y.H., Lee, S.S., Stiemer, S. (2009). Structural resistance of longitudinal double plates-toRHS connections, J. Constr. Steel Res., 65(4), pp.940-947. DOI: 10.1016/j.jcsr.2008.06.001.

[2] Shao, Y.B., Lie, S.T., Chiew, S.P. (2010). Static strength of tubular T-joints with reinforced chord under axial compression, Adv. Struct. Eng., 13(2), pp. 369-377. DOI: 10.1260/1369-4332.13.2.369.

[3] Teich, S., Otto, J., Bösche, T. (2016). Das Ottendorfer Viadukt - Entwurf und Ausführung einer außergewöhnlichen Stahlbogenbrücke, Stahlbau, 85(2), pp. 112-125. DOI: 10.1002/stab.201610359.

[4] Cao, J.J., Packer, J.A., Yang, G.J. (1998). Yield line analysis of RHS connections with axial loads, J. Constr. Steel Res., 48(1), pp. 1-25. DOI: 10.1016/S0143-974X(98)90143-2.

[5] Kosteski, N., Packer, J.A. (2003). Longitudinal plate and through plate-to-hollow structural section welded connections, J. Struct. Eng., 129(4), pp. 478-486. DOI: 10.1061/(ASCE)0733-9445(2003)129:4(478).

[6] Hassan, M.M., Ramadan, H., Abdel-Mooty, M., Mourad, S.A. (2015). Experimental and numerical study of one-sided branch plate-to-circular hollow section connections, Steel Compos. Struct., 19(4), pp. 877-895. DOI:10.12989/scs.2015.19.4.877.

[7] Voth, A.P., Packer, J.A. (2012). Branch Plate-to-Circular Hollow Structural Section Connections. I: Experimental Investigation and Finite-Element Modeling, J. Struct. Eng., 138(8), pp. 995-1006. DOI: $10.1061 /$ (asce)st.1943-541x.0000505.

[8] Wardenier, J., Packer, J.A., Puthli, R. (2018). Simplified design equations for Plate-to-CHS T and X joints for use in codes, Steel Constr.,11(2), pp. 146-161. DOI: 10.1002/stco.201810017.

[9] Fawzy, H. M., Mustafa, S. A. A., AbdEl-Badie A. E., (2020). Thermal Effect on Bond Strength of Rubberized Concrete Filled Steel Tubular Sections, Frattura ed Integrità Strutturale, 53, pp. 353-371. DOI: 10.3221/IGF-ESIS.53.28

[10] Kim, W.B., Shin, K.J., Lee, H.D., et al. (2015). Strength equations of longitudinal plate-to-circular hollow section (CHS) joints. International Journal of Steel Structures 15(2), pp. 499-505. DOI: 10.1007/s13296-015-6018-1

[11] Xu, F., Chen, J., Jin, W.L. (2016). Experimental investigation of concrete-filled steel tubular longitudinal gusset plate connections, J. Constr. Steel Res., 124, pp. 163-172. DOI: 10.1016/j.jcsr.2016.04.019.

[12] Yang, J., Sheehan, T., Dai, X.H., Lam, D. (2015). Experimental study of beam to concrete-filled elliptical steel tubular column connections, Thin-Walled Struct.,95, pp. 16-23. DOI: 10.1016/j.tws.2015.06.009.

[13] Willibald, S., Packer, J.A., Voth, A.P., Zhao, X. (2006). Through-plate joints to elliptical and circular hollow sections. Tubular Structures XI - Proceedings of the 11th International Symposium and IIW International Conference on Tubular Structures.pp. 221-228, Taylor \& Francis, Québec, Canada.

[14] Liu, Y., Xiong, Z., Feng, Y., Jiang, L. (2017). Concrete-filled rectangular hollow section X joint with Perfobond Leister rib structural performance study: Ultimate and fatigue experimental Investigation, Steel Compos. Struct., 24(4), pp. 455-465. DOI: $10.12989 /$ scs.2017.24.4.455.

[15] Liu, Y., Xiong, Z., Luo, Y., Cheng, G., Liu, G., Yang, J. (2015). Double-composite rectangular truss bridge and its joint analysis, J. Traffic Transp. Eng. (English Ed.), 2(4), pp. 249-257. DOI: 10.1016/j.jtte.2015.05.005.

[16] Davies, G., Packer, J.A. (1982).Predicting the strength of Branch plate-RHS connections for punching shear, Canadian journal of civil engineering. 9(3), pp. 458-467.

[17] Kosteski, N. (2001). Branch plate-to-rectangular hollow structural section connections, Ph.D. Thesis, University of Toronto, Toronto

[18] Simulia, D.S. (2014). Abaqus 6.14, Abaqus Analysis User's Manual.

[19] FIB Bulletin No.65 (2012). Model Code 2010, vol. 1. Lausanne, Switzerland

[20] Jankowiak, T., Lodygowski, T. (2005). Identification of parameters of concrete damage plasticity constitutive model, Found. Civ. Environ., 6(1), pp. 53-69.

[21] Ma, Y.S., Wang, Y.F., Mao, Z.K. (2011). Creep effects on dynamic behavior of concrete filled steel tube arch bridge. Structural Engineering \& Mechanics 37(3), pp. 321. DOI: 10.12989/sem.2011.37.3.321 